\title{
Regulation of gene expression by glucose
}

\author{
P. Ferré \\ U465 INSERM, Centre Biomédical des Cordeliers, 15 rue de L'Ecole de Médecine, 75270 Paris Cedex 06, France
}

\begin{abstract}
Fatty acid synthase (EC 2.3.1.85) is an enzyme involved in the lipogenic pathway allowing fatty acid synthesis from glucose. Glucose up-regulates the transcription of the fatty acid synthase gene in both adipocytes and hepatocytes, with insulin having only an indirect role. The signal metabolite could be glucose-6-phosphate rather than glucose itself. The glucose response element of the fatty acid synthase gene has not yet been precisely identified, although $\mathrm{a}-2 \mathrm{~kb}$ region of the fatty acid synthase promoter is sufficient to confer nutritional responsiveness to a reporter gene. ADD1/SREBP1, a b-HLH-LZ transcription factor belonging to the sterol regulatory elementbinding protein family might be involved in the transduction of the glucose effect. Finally, the stimulatory effect of glucose on the expression of the fatty acid synthase gene is inhibited by the activation of AMP-activated protein kinase. Interestingly enough, AMP-activated protein kinase is structurally and functionally related to the yeast SNF1 protein kinase complex which is essential for the transcriptional activation of glucose-repressed genes in Saccharomyces cerevisiae.
\end{abstract}

\section{Résumé}

\begin{abstract}
La synthase des acides gras est une enzyme impliquée dans la voie de la lipogenèse qui permet la synthèse de lipides à partir de glucides. Le glucose active la transcription de la synthase des acides gras, à la fois dans l' adipocyte et l'hépatocyte, l'insuline n'ayant qu'un rôle indirect. Le métabolite signal pourrait être le glucose-6-phosphate plutôt que le glucose lui-même. L'élément de réponse au glucose n'a pas été précisément identifié, bien qu'un fragment de $-2 \mathrm{~kb}$ du promoteur de la synthase des acides gras soit suffisant pour conférer à un gène rapporteur une réponse aux nutriments. ADD1/SREBP1, un facteur de transcription de type b-HLH-LZ, appartenant à la famille des protéines liant les éléments de réponse aux stérols (sterol regulatory element-binding protein) pourrait être impliqué dans la transmission du message glucose. Enfin, l'effet stimulateur du glucose sur l'expression de la synthase des acides gras est inhibé par l'activation de la kinase activée par l'AMP. Il est intéressant de constater que cette kinase est proche fonctionnellement et structuralement de la kinase SNF1 de levure, kinase essentielle pour l'activation transcriptionnelle de gènes réprimés par le glucose chez Saccharomyces cerevisiae.
\end{abstract}

Glucose: Gene regulation: Fatty acid synthase

Regulation of gene expression by nutrients is an important mechanism in the adaptation of mammals to their nutritional environment. This is especially true for enzymes involved in the storage of energy, such as the lipogenic and glycolytic enzymes in the liver. Fatty acid synthase (EC 2.3.1.85; FAS) is a key enzyme of lipogenesis, a pathway allowing de novo synthesis of acyl-CoA from glucose. In rodents, lipogenesis occurs in both liver and adipose tissue and is active in the case of low-fat high-carbohydrate diets. The activity of FAS follows a similar pattern. Interestingly enough, its regulation occurs mainly at a transcriptional level.

\section{Glucose up-regulates fatty acid synthase gene transcription}

In both adipose tissue and hepatocytes, in vivo and in vitro experiments have shown that glucose up-regulates FAS expression through a transcriptional effect (Girard 
et al. 1997). In order to be effective, glucose must be metabolized. In the liver, the effect of glucose requires the presence of glucokinase (EC 2.7.1.2), the enzyme responsible for the phosphorylation of glucose to glucose-6phosphate (Prip-Buus et al. 1995). In the absence of glucose, insulin by itself is unable to induce the expression of FAS. In the absence of insulin, the effect of glucose on FAS transcriptional rate is strongly decreased in adipose tissue and nearly absent in cultured hepatocytes (Foufelle et al. 1992; Prip-Buus et al. 1995). In fact, insulin has an indirect role, either increasing glucose transport and metabolism through the translocation of the insulin-responsive glucose transporter GLUT4 to the plasma membrane in adipocytes, or by allowing glucose metabolism to proceed in the liver by stimulating glucokinase activity.

\section{Glucose-6-phosphate could be the signal metabolite}

Based on the following evidence, we have proposed that glucose-6-phosphate could be the signal metabolite. The effect of glucose is mimicked by 2-deoxyglucose, a glucose analogue which is not further metabolized after its phosphorylation into 2-deoxyglucose-6-phosphate, which accumulates in the cell (Foufelle et al. 1992). Intracellular glucose-6-phosphate concentration varies in parallel with the expression of FAS, whereas that of other potential metabolites does not (Mourrieras et al. 1997). Moreover, in vivo, the kinetics of hexose phosphate concentration fit with the time-related pattern of FAS gene induction. It must be pointed out that Doiron et al. (1996) have proposed that xylulose-5-phosphate, a metabolite belonging to the pentose-phosphate pathway, is the signal metabolite. The involvment of one or the other metabolite thus awaits confirmation.

\section{cis-Glucose response element and trans-acting factor}

The glucose response element of two other genes belonging to the lipogenic pathway, L-pyruvate kinase (EC 2.7.1.40) and the S14 genes, the expression of which is also stimulated by glucose, has been identified. It consists of two E-box (or E-box like) sequences (5'-CAnnTG-3') separated by five nucleotides (Towle et al. 1997). The glucose response element of the FAS gene has not yet been identified, although experiments in transgenic mice suggest that the $-2 \mathrm{~kb}$ region of the FAS promoter is sufficient to confer the ability to be regulated by nutrients (Girard et al. 1997). The E-box described in the L-pyruvate kinase and S14 glucose response element is a binding site for a specific class of transcription factors. All these proteins have a structure which includes a basic domain (a sequence of amino acids rich in lysine and arginine residues); immediately C-terminal to the basic domain are two amphiphatic $\alpha$-helices connected by a loop, followed by a conserved heptad leucine repeat or zipper motif where a leucine residue is present as every seventh residue in an $\alpha$-helix, implying that all hydrophobic residues are on the same side of the helix, a feature which should play a role in dimeriza- tion. These different structures are involved in the binding to DNA and in protein-protein interactions.

Among the transcription factors belonging to this class of proteins, USF/MLTF (for upstream stimulatory factor (major late transcription factor), designated USF) has been implicated as the mediator of glucose action (Vaulont \& Kahn, 1994; Towle et al. 1997). The tissue distribution of this factor is ubiquitous and does not seem to be altered by the nutritional or hormonal status. For the two genes considered (L-pyruvate kinase and S14), binding of USF to the E-box of the glucose response element has been demonstrated, exclusive of other transcription factors. However, the involvement of USF as the factor involved in the glucose responsiveness of the L-pyruvate kinase and S14 genes is still a disputed issue (Towle et al. 1997; Foufelle et al. 1998). Concerning the FAS gene, recent evidence suggests that ADD1/SREBP1, a b-HLH-LZ transcription factor belonging to the sterol regulatory element-binding protein family, might be involved in the transduction of the glucose effect (Foufelle et al. 1998). Overexpression of this factor in transgenic mice led to a dramatically increased expression of hepatic FAS and to liver steatosis (Shimano et al. 1996). In adipocyte cell lines, ADD1/SREBP1 is essential for the activation of the FAS promoter through the presence of an E-box in its proximal promoter (Kim et al. 1998). Moreover, the expression of ADD1/SREBP1 itself is controlled positively by insulin, thus establishing a link between this transcription factor and the dietary carbohydrate status (Kim et al. 1998). Further studies are necessary to identify definitively the transcription factor involved in the glucose effect.

\section{The glucose effect can be antagonized by a specific kinase}

Glucose-induced activation of FAS gene transcription is markedly reduced by incubation of the cells with okadaic acid, an inhibitor of protein phosphatase 1 and 2A, suggesting that the glucose stimulatory effect could involve a dephosphorylation mechanism (Foretz et al. 1998). A similar reduction in glucose-activated FAS gene expression is obtained by incubation with 5-amino-imidazolecarboxamide riboside, a cell-permeable activator of the AMP-activated protein kinase (AMPK; Foretz et al. 1998). Expression of the S14 and L-pyruvate kinase genes is also down-regulated when AMPK is activated (Leclerc et al. 1998). AMPK phosphorylates and inactivates acetyl-CoA carboxylase (EC 6.4.1.2) and 3-hydroxy-3-methylglutarylCoA reductase ( $E C$ 1.1.1.34), resulting in the inhibition of both lipogenesis and cholesterol synthesis. These two pathways utilize acetyl-CoA as a substrate, which mostly originates from glucose. The action of AMPK on FAS gene expression would thus allow the potential for the coordinated regulation of lipid synthesis from glucose in both the short and long term. Interestingly enough, AMPK is structurally and functionally related to the yeast SNF1 protein kinase complex which is essential for the transcriptional activation of glucose-repressed genes in Saccharomyces cerevisiae (Foufelle et al. 1998). The target (transcription factor?) of AMP-activated kinase is presently unknown. 


\section{Acknowledgements}

Part of this work was supported by Grant 96/3011 from the European Economic Community Fair programme.

\section{References}

Doiron B, Cuif MH, Chen R \& Kahn A (1996) Transcriptional glucose signaling through the glucose response element is mediated by the pentose phosphate pathway. Journal of Biological Chemistry 271, 5321-5324.

Foretz M, Carling D, Guichard C, Ferré P \& Foufelle F (1998) AMP-activated protein kinase inhibits the glucose-activated expression of fatty acid synthase gene in rat hepatocytes. Journal of Biological Chemistry 273, 14767-14771.

Foufelle F, Girard J \& Ferré P (1998) Glucose regulation of gene expression. Current Opinion in Clinical Nutrition and Metabolic Care 1, 323-328.

Foufelle F, Gouhot B, Pégorier JP, Perdereau D, Girard J \& Ferré P (1992) Glucose stimulation of lipogenic enzyme gene expression in cultured white adipose tissue. Journal of Biological Chemistry 267, 20543-20546.

Girard J, Ferré P \& Foufelle F (1997) Mechanisms by which carbohydrates regulate expression of genes for glycolytic and lipogenic enzymes. Annual Review of Nutrition 17, 325-352.
Kim J, Sarraf P, Wright M, Yao K, Mueller E, Solanes G, Lowell B \& Spiegelman B (1998) Nutritional and insulin regulation of fatty acid synthetase and leptin gene expression through ADDI/SREBP. Journal of Clinical Investigation 101, 1-9.

Leclerc I, Kahn A \& Doiron B (1998) The 5'-AMP-activated kinase inhibits the transcriptional stimulation by glucose in liver cells, acting through the glucose response complex. FEBS Letters $\mathbf{4 3 1}$, $180-184$.

Mourrieras F, Foufelle F, Foretz M, Morin J, Bouché S \& Ferré P (1997) Induction of fatty acid synthase and S14 gene expression by glucose, xylitol and dihydroxyacetone in cultured rat hepatocytes is closely correlated with glucose 6-phosphate concentrations. Biochemical Journal 326, 345-349.

Prip-Buus C, Perdereau D, Foufelle F, Maury J, Ferré P \& Girard J (1995) Induction of fatty acid synthase gene expression by glucose in primary culture of rat hepatocytes. European Journal of Biochemistry 230, 309-315.

Shimano H, Horton JD, Hammer RE, Shimomura I, Brown MS \& Goldstein JL (1996) Overproduction of cholesterol and fatty acids causes massive liver enlargement in transgenic mice expressing truncated SREBP-1a. Journal of Clinical Investigation 98, 1575-1584.

Towle HC, Kaytor EN \& Shih HM (1997) Regulation of the expression of lipogenic enzyme genes by carbohydrate. Annual Review of Nutrition 17, 405-433.

Vaulont S \& Kahn A (1994) Transcriptional control of metabolic regulation genes by carbohydrates. FASEB Journal 8, 28-34. 
